\title{
ANÁLISE QUALITATIVA DOS ITENS DE EDUCAÇÃO FÍSICA VIA DESCRITORES DO EXAME NACIONAL DO ENSINO MÉDIO (ENEM)
}

José Airton F Pontes $\mathrm{Jr}^{1,2^{*}}$, Ana Géssica Silva ${ }^{3}$, Leandro A. Sousa ${ }^{4}$, Raphaell M. Martins ${ }^{5}$, Leandro S. Almeida ${ }^{1}$

${ }^{1}$ Universidade do Minho, Braga, Portugal, ${ }^{2}$ Universidade Estadual do Ceará (UECE), ${ }^{3}$ Centro Universitário Católica de Quixadá (UniCatólica), ${ }^{4}$ Universidade Federal do Ceará (UFC), ${ }_{*}^{5}$ Universidade Estadual Paulista (UNESP)

japontesjr@gmail.com

Submetido 14/03/2016 - Aceito 08/12/2017

DOI: $10.15628 /$ holos.2017.4272

\section{RESUMO}

A Educação Física está presente no Exame Nacional do Ensino Médio (ENEM) desde 2009 na área de Linguagens, Códigos e suas Tecnologias. Tendo isto em conta, este estudo avaliou e classificou os itens de Educação Física do ENEM quanto às habilidades da Competência 3 da Matriz de Referência do exame. Foram analisadas as provas válidas de 2009 a 2015, em que foram identificados 19 itens, sendo 5, 6 e 8 itens referentes às habilidades $\mathrm{H} 11, \mathrm{H} 9$ e $\mathrm{H} 10$, respectivamente. Através das análises realizadas podese observar que os itens de Educação Física do ENEM contemplam a competência e as habilidades solicitadas em sua Matriz de referência.

PALAVRAS-CHAVE: Avaliação Educacional, Educação Física e Treinamento, Conhecimento, Teste de Admissão Acadêmica

\section{QUALITATIVE ANALYSIS OF PHYSICAL EDUCATION ITEMS VIA NATIONAL EXAM OF UPPER SECONDARY EDUCATION DESCRIPTORS}

\begin{abstract}
Physical Education has been present on National Exam of Upper Secondary Education (ENEM) since 2009 in Languages, Codes and its Technologies area. Taking this into account, the research evaluated and classified the Physical Education items at ENEM regarding the skills of Competency 3 from the exam Reference Matrix. The
\end{abstract}

valid tests from 2009 to 2015 have been analyzed, in which 19 items were identified, whereas 6,8 and 5 items refer to skills $\mathrm{H} 9, \mathrm{H} 10$ and $\mathrm{H} 11$, respectively. Through these analysis, it can be observed that the Physical Education items at ENEM contemplate the competence and skills required in its Reference Matrix.

KEYWORDS: Educational Assessment, Physical Education and Training, Knowledge, College Admission Test 


\section{INTRODUÇÃO}

O Exame Nacional do Ensino Médio (ENEM) é uma avaliação em larga escala que procura avaliar os conhecimentos dos alunos participantes. Criado em 1998, o Exame apresenta, entre outros, os objetivos de ser um parâmetro de auto avaliação dos alunos para a continuidade da formação e inserção no mundo do trabalho, estabelecer um parâmetro de avaliação para os egressos das modalidades de Ensino Médio e assumir a nota da prova como via de acesso ao Ensino Superior (Brasil, 1998a).

Em 2014, o ENEM obteve mais de 9,5 milhões de candidatos inscritos e em 2015 foram pouco mais de 7,7 milhões. O aumento do número de participantes ocorre desde 2009 com a implantação do SISU - Sistema de Seleção Unificada (Brasil, 2015). Com essa amplitude adquirida, o ENEM tornou-se uma forma de avaliar a qualidade dessa etapa de ensino, embora receba críticas pela dificuldade de atender a diversidade nacional dos conteúdos da Educação Básica e a dependência desse Exame nas políticas de financiamento (Corti, 2013). Assim, pode-se considerar o ENEM um grande indicador da qualidade do Ensino Médio, já que as avaliações em larga escala são parâmetros para o diagnóstico da qualidade do ensino e definição de políticas públicas educacionais (Vianna, 2003).

Sendo o ENEM uma avaliação que possibilita o ingresso dos alunos no Ensino Superior, as escolas públicas e privadas passaram a atuar em função da preparação dos alunos com aulas e simulados especificamente para esse modelo de prova ao longo de todo o Ensino Médio. Tal prática, logicamente, visa a obtenção dos melhores resultados. Além disso, os órgãos governamentais tomam iniciativas, tais como, oferecimento de cursos de qualificação com o objetivo de expandir a cultura da avaliação (Minhoto, 2008). Também é importante relatar que as provas e os gabaritos, bem como a Matriz de Referência do ENEM, são disponibilizados pelo Instituto Nacional de Estudos e Pesquisas Educacionais Anísio Teixeira (INEP), que possibilita a análise tanto qualitativa quanto quantitativa das questões, tecnicamente conhecidas como itens. A Matriz de Referência desse exame é composta de competências e habilidades que objetiva auxiliar os elaboradores de Itens e a preparação adequada dos participantes do ENEM (Brasil, 2012).

Antes de avançarmos, importa que assumimos aqui "competências" no sentido de uma habilidade de ordem mais geral e ampla, enquanto que "habilidade" são competências de caráter 
mais específico e particular (Macedo, 2005). Pode-se entender como competente aquele que executa bem uma tarefa, em que precisa utilizar algumas habilidades para tanto. Por exemplo, um professor é competente ao ensinar bem, sendo que isso implica habilidades de relacionamento, oralidade, planejamento, criatividade, etc.

A componente curricular de Educação Física está presente no ENEM desde 2009 na área de Linguagens, Códigos e suas Tecnologias (Brasil, 2012). Isso pode ter sido em decorrência da presença de objetivos na dimensão cognitiva nos Parâmetros Curriculares Nacionais (PCN's) de Educação Física (Brasil, 2000), servindo também como norteador para professores de Educação Física, tanto para aplicação de conteúdo como para avaliação da aprendizagem.

Dentre as críticas podemos apontar as condições do ensino dos conteúdos, pois é recorrente o uso de aulas no contra-turno, dificultando a participação e aprendizagem discente, para além do caráter facultativo das aulas de Educação Física no Ensino Noturno e da diminuição da sua importância ou exclusão do componente curricular no 3 o ano do Ensino Médio (Fensterseifer, González \& Schwengber, 2011; Fernandes, Rodrigues \& Nardon, 2013).

No entanto, é superficial apontar que essa inserção da Educação Física no ENEM legitima essa componente curricular à comunidade escolar, mas é evidente o seu impacto no cotidiano docente da área em relação ao planejamento e avaliação dos conteúdos ministrados (Beltrão, 2014).

Estudos têm sido realizados com os itens em outras áreas no ENEM como a Física (Gonçalves Jr \& Barroso, 2014; Hernandes \& Martins, 2013), a Biologia (Santos \& Cortelazzo, 2013), na área de Ciências da Natureza (Melo, Araújo, Santos, Carvalho \& Costa, 2014), em relação à História do Tempo Presente (Souza \& Stamatto, 2014). No entanto, pesquisas que investiguem os itens (questões) de Educação Física nesse exame ainda são escassas.

Em relação aos itens de Educação Física no ENEM, Souza Júnior, Diniz, Ditomaso e Darido (2012) analisaram qualitativamente as questões das provas de 2009 a 2011 e identificaram que das 16 questões relativas à área, 7 eram relacionados ao bloco de conteúdo Conhecimento sobre o Corpo. Os autores concluem o estudo apontando que os itens da área estão relacionados a conhecimentos sobre saúde e outros conteúdos previstos nos Parâmetros Curriculares (PCN) da Educação Física, tais como atividades rítmicas e expressivas, visto que os PCN da área no Ensino Médio estão relacionados à temática da cultura corporal de movimento. Porém, não realizaram essa análise via descritores do ENEM na área de Linguagens, Códigos e suas Tecnologias. 
A análise dos itens dessa disciplina tem sido realizada a partir da Dimensão Cognitiva da Taxonomia dos Objetivos Educacionais de Bloom (Pontes Jr, Sousa \& Silva, 2015), em que os classificam em cada nível cognitivo tendo como parâmetro os demais da área de Linguagens, Códigos e suas Tecnologias, pois é na Competência 3 que os descritores da Educação Física estão inseridos na Matriz de Referência (Brasil, 2012). Esta correspondência parte do pressuposto que o conhecimento das habilidades exigidas no exame para a componente curricular Educação Física, como para as outras áreas, pode auxiliar os professores do Ensino Médio a melhor planejar e elaborar suas aulas, bem como subsidiar os alunos na preparação para essa avaliação.

Assim, para a realização do presente estudo apresenta-se o seguinte problema: Quais as habilidades da Matriz de Referência do ENEM para a disciplina de Educação Física são mais exigidas? Desse modo, a pesquisa tem como objetivo classificar os itens de Educação Física presentes na área de Linguagens, Códigos e suas Tecnologias do ENEM.

\section{PROCEDIMENTOS METODOLÓGICOS}

O estudo é do tipo exploratório, documental e de natureza qualitativa, visto que na vertente técnica de elaboração de itens apresenta-se como necessária a organização conceitual dos itens que irão representar indiretamente as variáveis latentes almejadas no teste como parte prévia de uma análise psicométrica.

Foram analisadas as provas válidas do ENEM nas edições de 2009 a 2015, em que os itens de Educação Física estavam presentes na Matriz de Referência do Exame na área de Linguagens, Códigos e suas Tecnologias. As provas estão disponíveis no site do INEP.

Em 2009 e 2010 as provas possuíam capa azul com gabarito único para todos os candidatos. Entretanto, a partir de 2011, passou-se a utilizar quatro gabaritos diferentes para a mesma prova, sendo estes diferenciados pelas cores da capa dos cadernos. Não foram considerados no estudo os itens do exame anulado no ano de 2010, em que foi necessário realizar uma segunda aplicação do exame.

Inicialmente realizou-se a identificação dos itens referentes à disciplina nas provas de Linguagens, Códigos e suas Tecnologias, em que foi possível perceber que eram os mesmos nos demais cadernos de provas em cada ano, diferenciando apenas na ordem de posição. Com isso, a 
análise seguiu com referência nas provas de capa azul, em que foi classificado quanto à habilidade especifica da Matriz de Referência (Brasil, 2015):

Competência de área 3 - Compreender e usar a linguagem corporal como relevante para a própria vida, integradora social e formadora da identidade.

H9 - Reconhecer as manifestações corporais de movimento como originárias de necessidades cotidianas de um grupo social.

H10 - Reconhecer a necessidade de transformação de hábitos corporais em função das necessidades cinestésicas.

H11 - Reconhecer a linguagem corporal como meio de interação social, considerando os limites de desempenho e as alternativas de adaptação para diferentes indivíduos.

Para a identificação da habilidade que corresponde ao item foi utilizada a técnica de análise temática (Minayo, 2000) em que se observou o conteúdo exigido no item e se o comando (enunciado) estava relacionado a habilidade pretendida. Na apresentação dos resultados foram utilizadas tabelas e exposto um exemplo de item para cada habilidade.

\section{RESULTADOS E DISCUSSÃO}

Foi identificado um total de 19 itens em que se contemplam os conteúdos de Educação Física e em que conhecimentos adquiridos na componente curricular são necessários para sua resolução. O Quadro 1 apresenta a posição dos itens em cada caderno de questões dos anos de 2009 a 2015.

Quadro 1 - Números dos itens de Educação Física dos cadernos de questões de cada ano.

\begin{tabular}{|c|c|c|c|c|c|c|c|}
\hline \multirow{2}{*}{$\begin{array}{c}\text { CADERNO DE } \\
\text { PROVA }\end{array}$} & \multicolumn{7}{|c|}{ ANO DE APLICAÇÃO DO ENEM } \\
\hline & 2009 & $2010^{*}$ & 2011 & 2012 & 2013 & 2014 & 2015 \\
\hline Amarela & $\mathbf{N}$ & $\mathbf{N}$ & $\begin{array}{c}96,105 \\
108 \\
134\end{array}$ & $\begin{array}{l}109, \\
113, \\
132\end{array}$ & $\begin{array}{l}101 \\
103, \\
108\end{array}$ & $\begin{array}{l}103 \\
104\end{array}$ & 96,128 \\
\hline Azul & $\begin{array}{l}103 \\
134\end{array}$ & $\begin{array}{c}96,118, \\
127\end{array}$ & $\begin{array}{c}96,105 \\
108, \\
133\end{array}$ & $\begin{array}{c}96,100, \\
115\end{array}$ & $\begin{array}{c}97,108, \\
111\end{array}$ & 97,98 & 97,124 \\
\hline Cinza & $\mathbf{N}$ & $\mathbf{N}$ & $\begin{array}{c}97,104 \\
107 \\
135\end{array}$ & $\begin{array}{c}96,103 \\
129\end{array}$ & $\begin{array}{c}98,101, \\
108\end{array}$ & $\begin{array}{l}108 \\
109\end{array}$ & 96,107 \\
\hline Rosa & $\mathbf{N}$ & $\mathbf{N}$ & $\begin{array}{c}97,104 \\
107\end{array}$ & $\begin{array}{c}96,99 \\
113\end{array}$ & $\begin{array}{c}98,110, \\
118\end{array}$ & $\mathbf{N}$ & 96,116 \\
\hline
\end{tabular}




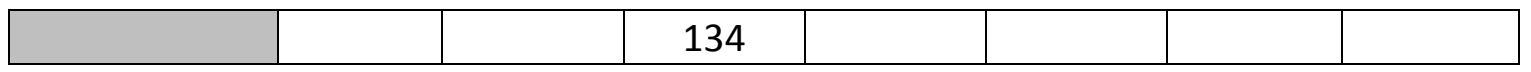

Fonte: Elaboração dos Autores.

Legenda: N: não houve este caderno de prova. * Caderno de prova da segunda aplicação.

O Quadro 2 apresenta a posição do item no caderno de provas, o número de questões e as habilidades contempladas. No ano de 2009 continha 2 itens referentes às habilidades H10 e H11. Nos anos de 2010, 2012, 2013 e 2016 contemplaram 3 itens da disciplina, sendo um para cada habilidade. Nos anos de 2011 e 2017 foram exigidos 4 itens, sendo 1 para a habilidade H9, 2 para H10 e 1 para H11. Em 2014, 2 itens foram identificados correspondendo às habilidades H9 e H10. Por fim em 2015 esteve presente 2 itens da disciplina, representando as habilidades H9 e H10. Observa-se continuidade e diversidade dos temas da Competência 3 na prova de Linguagens nesses anos, tal como apresentado por Pontes Jr, Silva e Sousa (2015) que discutem sobre os níveis de complexidade dos itens e também em Sousa, Braga e Trompieri Filho (2016) onde há discussões sobre mudanças pedagógicas de componente curricular na escola, como aulas teóricas e provas escritas.

Quadro 2 - Classificação dos itens quanto à habilidade.

\begin{tabular}{|c|c|c|c|c|}
\hline \multirow{2}{*}{ Ano } & \multicolumn{3}{|c|}{ Habilidades } & \multirow{2}{*}{ Total } \\
\cline { 2 - 4 } & $\mathrm{H} 9$ & $\mathrm{H} 10$ & $\mathrm{H} 11$ & \\
\hline 2009 & & 103 & 134 & 2 \\
\hline 2010 & 96 & 127 & 118 & 3 \\
\hline 2011 & 105 & 96,133 & 108 & 3 \\
\hline 2012 & 100 & 96 & 115 & 3 \\
\hline 2013 & 97 & 108 & 111 & 3 \\
\hline 2014 & 97 & 98 & & 2 \\
\hline 2015 & 124 & 97 & & 2 \\
\hline 2016 & 130 & 129 & 128 & 3 \\
\hline 2017 & 31 & 26 & 19,42 & 4 \\
\hline Total & 6 & 8 & 5 & 25 \\
\hline
\end{tabular}

Fonte: Elaboração dos Autores.

Ao analisar os itens de Educação Física do exame foi identificado que cada item corresponde a apenas uma habilidade, o que do ponto de vista métrico é importante. No entanto, em outras disciplinas isso não tem acontecido. Gonçalves Jr e Barroso (2014), por exemplo, identificaram que nem todas as habilidades da Matriz de Referência da disciplina de Física são requisitadas nos itens do ENEM e que uma mesma questão contempla mais que uma habilidade. Estes aspectos são considerados problemáticos já que as notas dos candidatos são 
dadas pela Teoria de Resposta ao Item e esta metodologia de análise pressupõe a unidimensionalidade do item, indicando que este deve referir-se apenas a uma habilidade.

Estas dificuldades ocorrem também com as provas noutras áreas curriculares. Em outra análise dos itens de Física do ENEM identificou-se muitos itens construídos em uma perspectiva tradicional, no sentido de que, mesmo apresentado em uma situação contextualizada, esta em nada contribui para a resolução da questão, de modo que, se for retirada, os elementos restantes são suficientes para a resolução do problema (Hernandes \& Martins, 2013). Por sua vez, Santos e Cortelazzo (2013), ao analisarem os itens de Biologia do ENEM em relação a Matriz de Referência da disciplina, observam que abordam as habilidades de forma parcial, em que os fenômenos biológicos no comando do item não estão referidos adequadamente à habilidade pretendida, mas que, no entanto, o conteúdo apresentava-se de forma contextualizada, o que exige não só a aprendizagem de conceitos específicos, isolados, mas esses inseridos dentro de uma realidade, o que deve constituir o perfil do estudante do Ensino Médio.

Uma possibilidade de análise dos itens do ENEM é com referência a Dimensão Cognitiva da Taxonomia dos Objetivos Educacionais de Bloom, que atribui níveis de raciocínio cognitivo aos objetivos. Esse foco tem sido realizado com os itens desse exame (Silva \& Martins, 2014; Cintra, Marques Júnior \& Sousa, 2014; Marcelino \& Recena, 2011). No que se refere especificamente a componente curricular Educação Física também se encontra na pesquisa de Pontes Jr, Sousa e Silva (2015), em que os autores identificaram 17 itens de Educação Física de 2009 a 2014, em que a maioria das questões apresentou baixo nível de exigência cognitiva, concentrando-se nos níveis de Conhecimento e Compreensão. Esses resultados ainda podem ser reflexo das ações pedagógicas, curriculares e de políticas educacionais incipientes para a Educação Física na escola que ainda luta para ampliar de sua legitimação e que tem o Exame como um importante fator regulador que está potencializado alternativas de melhorias.

Para ilustrar a classificação realizada no Quadro 2, são apresentados três exemplos de itens do Enem referente a cada habilidade do Exame. 0 item apresentado na Figura 1 é classificado na habilidade H9 - "Reconhecer as manifestações corporais de movimento como originárias de necessidades cotidianas de um grupo social". 


\section{QUESTÃO 97 \\ O jogo é uma atividade ou ocupação voluntária, exercida dentro de certos e determinados limites de tempo e de espaço, segundo regras livremente consentidas, mas absolutamente obrigatórias, dotado de um fim em si mesmo, acompanhado de um sentimento de tensão e de alegria e de uma consciência de ser diferente da "vida quotidiana". \\ HUIZINGA, J. Homo ludens: ojogo como elemento da cultura. Sảo Paulo: Perspectiva, 2004. \\ Segundo o texto, o jogo comporta a possibilidade de fruição. Do ponto de vista das práticas corporais, essa fruição se estabelece por meio do(a) \\ A fixação de táticas, que define a padronização para maior alcance popular. \\ B competitividade, que impulsiona o interesse pelo sucesso. \\ C refinamento técnico, que gera resultados satisfatórios. \\ (D) caráter lúdico, que permite experiências inusitadas. \\ $\boldsymbol{\Theta}$ uso tecnológico, que amplia as opções de lazer.}

Figura 1 - Item número 97 do caderno de questões azul do ano de 2013. Fonte: Brasil (2013).

O item acima aborda o jogo (ou brincadeiras) como uma expressão da cultura que possibilita o ser humano experimentar sentimentos diferenciados do seu dia-a-dia. Segundo Mattos e Neira (2008) gestos, expressões e movimentos, que podem ser observados na prática do jogo, são manifestações corporais e é a Educação Física que possibilita a construção e conhecimento sobre essa cultura que envolve o próprio corpo. Também se pode perceber que o conteúdo abordado no item é um dos temas mais explorado pela Educação Física escolar (Brasil, 1998b), e se usado com intencionalidade pedagógica pode trazer grandes benefícios para a formação do educando. Decian, Ivo e Marin (2015) apontam para a necessidade de (maior efetividade) na utilização desse na formação de professores na área de Educação Física, principalmente o seu tratamento sistemático em mais disciplinas ao longo da graduação. A Base Nacional Curricular Comum (BNCC) poderá auxiliar os programas educacionais de diversas áreas, inclusive da Educação Física, e os jogos e esportes continuam como um dos principais temas direcionadores para a atuação docente.

No Ensino Médio o jogo tem uma característica diferenciada do Ensino Fundamental e da Educação Infantil, pois como está explícita na problemática do item, a ênfase é em conhecer aspectos teóricos dessa manifestação, tais como, características, contexto na qual está inserido e suas influências, como também quais a implicações da sua prática do desenvolvimento do ser humano. 
O item da Figura 2 é classificado na habilidade H10 - "Reconhecer a necessidade de transformação de hábitos corporais em função das necessidades cinestésicas".

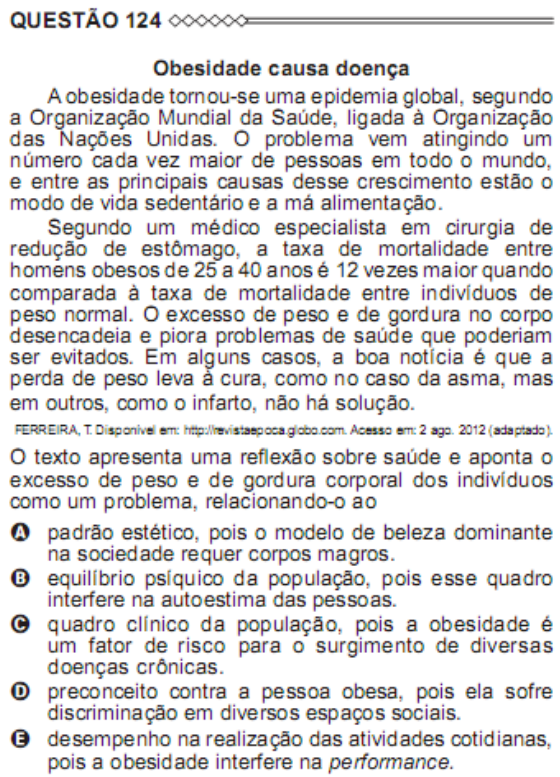

Figura 2 - Item número 124 do caderno de questões azul do ano de 2015. Fonte: Brasil (2015).

A saúde é um tema transversal dos $\mathrm{PCN}^{\prime}$ s que deve estar relacionada às temáticas tradicionais das disciplinas (Brasil, 1998b). Atividade física como um componente da saúde contribui para prevenção de doenças e promoção de saúde (Nahas, Pires, Waltrick \& Bem, 1995). Sua inserção no âmbito escolar potencializa a tomada de consciência sobre os benefícios de sua prática regular (Nahas et al., 1995; Guedes \& Guedes, 1997; Guedes, 1999). Nesse sentido, Macêdo et al. (2015) identificam que a maioria dos alunos afirmam que nunca tiveram aula de musculação na disciplina, porém têm interesse no conteúdo, tendo em vista a aceitação desses alunos a mesma poderia torna-se conteúdo das aulas de Educação Física.

No estudo de Pontes Jr, Almeida e Trompieri Filho (2015), validou-se uma matriz de referência para avaliação em larga escala dos conteúdos da área da Atividade Física e Saúde que foi denominado Dimensão Biológico-Funcional em Educação Física escolar, o que pode contribuir na organização e parâmetro para a construção dos itens de Educação Física. Por outro lado, numa pesquisa de Zancha, Magalhães, Martins, Silva e Abrahão (2013) analisaram a prática e conhecimento de professores do Ensino Fundamental sobre a temática da saúde, tendo-se observado que os docentes trabalham a temática saúde, principalmente na dimensão conceitual, mas com dificuldades de ampliarem a atuação com esses conteúdos para perspectivas prática (procedimentais) e relacionais (atitudinais). Já no estudo de Spohr, Fontes, Rombaldi, Hallal e 
Azevedo (2014), com foco nos alunos como público da pesquisa, verificou-se um aumento de conhecimento sobre saúde apesar de não haver alteração no índice de atividade física dos alunos. Cabe refletir que tais mudanças nos níveis de conhecimento sobre determinado assunto (variável cognitiva) potencializa mudanças nos níveis de atitudes e ações procedimentais, mas nem sempre no tempo esperado. Sem ações mais efetivas, tal como aumento do número de horas de aula de Educação Física no Ensino Fundamental e no Ensino Médio, além de maior quantidade de formações permanentes aos docentes da área, os resultados dos maiores níveis de conhecimento em relação às mudanças de comportamento serão muito mais lentos.

Silveira e Silva (2011) avaliaram os conhecimentos sobre atividade física dos alunos do Ensino Médio, em que obtiveram um acerto de $63 \%$ dos escores, o que segundo os pesquisadores pode ser considerado baixo. Barros e Silva (2013) encontram resultado parecido ao analisar o conhecimento sobre atividade física e saúde de alunos do Ensino Médio da zona rural, obtiveram como resultado uma média de 35,8 de pontos de acerto, o que representa $60 \%$ dos escores das questões. Cardoso, Pereira, Afonso e Rocha Junior (2014) identificaram melhorias no conhecimento sobre aptidão física relacionada à saúde em alunos desse nível de ensino após uma intervenção com aulas teórica e práticas sobre o assunto.

Com isso, ressaltamos a importância do tema saúde e sua abordagem em avaliações em larga escala como o ENEM. Isso exige um olhar mais crítico dos alunos que se submetem a esse exame em relação a esse tema. Nesse contexto, o componente curricular Educação Física pode contribuir com a problematização desse assunto.

O item da Figura 3 é classificado na habilidade H11 - "Reconhecer a linguagem corporal como meio de interação social, considerando os limites de desempenho e as alternativas de adaptação para diferentes indivíduos". 


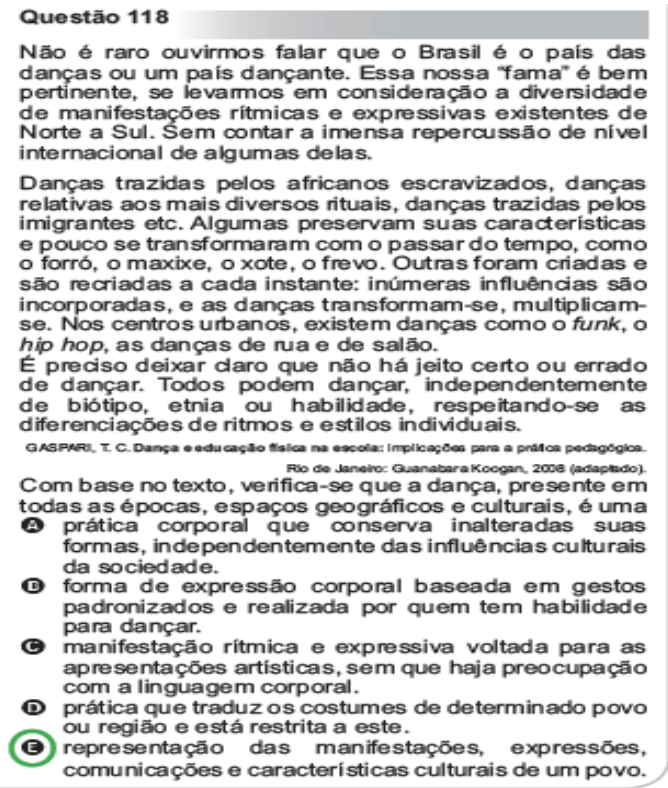

Figura 3 - Item número 118 do caderno de questões azul do ano de 2010. Fonte: Brasil (2010).

Os conteúdos relacionados com as Atividade Rítmicas e Expressivas, que podem ser tematizados tanto na Educação Física quanto na componente curricular Artes. Mas no caso do item em questão há de se enfatizar que ele se adequa a habilidade 11 da Competência 3 da Matriz de Referência do ENEM, no qual se refere aos conteúdos da Educação Física.

Deste modo, ressalta-se a importância de avaliações cognitivas desse conteúdo, também reforçado por Pontes Jr (2014) ao identificar que os docentes de Educação Física possuem nível de concordância satisfatório em relação aos descritores para avaliação cognitiva em larga escala direcionados para esse conteúdo. Com isso, discute que o conteúdo dança está sendo ministrado com mais efetividade pelos docentes da disciplina de Artes e Educação Física, mesmo com necessidade de aprimoramento docente em relação a esses conhecimentos rítmicos e expressivos em ambas a áreas. A presença desse conteúdo nos itens do ENEM reforça a necessidade de sua abordagem no Ensino Médio, em que um tratamento crítico, contextualizado e problematizador dos temas relacionados as manifestações culturais, políticas e sociais que as práticas corporais estão envolvidas e que os alunos podem se aproximar nas aulas.

\section{DISPOSIÇÕES FINAIS}

Através do estudo foi possível considerar que uma amostra de itens analisados de Educação Física do Exame Nacional do Ensino Médio (ENEM) contempla as competências e habilidades solicitadas em sua Matriz de Referência. Mais concretamente verificou-se que os 
itens abordam aspectos relevantes das propostas dos descritores da área com temas relacionados à saúde, esportes, jogos, dança, dentre outros.

Por outro lado, dado que o exame vem aumentando o número de inscritos consideravelmente, esta situação faz com que famílias escolas, instituições privadas e órgãos governamentais se mobilizem mais para preparação de seus participantes, na motivação e dedicação dos próprios alunos a esta disciplina curricular. No entanto, não deixamos de indicar que há uma adequação questionável desses diferentes entes envolvidos ao Exame, seja nos problemas do currículo invertido, seja na preparação técnica responder ao instrumento.

O aprimoramento técnico e cientifico, e a criação de matrizes de referência com conteúdo de Educação Física são necessárias para ampliar as possibilidades de estudos e pesquisas na área. As pesquisas têm apresentados avanços no aprimoramento técnico e pedagógico em relação às avaliações em larga escala na área de Educação Física e que esse estudo pode contribuir para o planejamento e crítica às formações no Ensino Superior e para atuação na escola. Exemplo disso está na pouca literatura sobre o assunto em livros, talvez um novo desafio bibliográfico em relação a psicometria, avaliação da aprendizagem e políticas educacionais em Educação Física escolar.

Percebe-se como limitação desse estudo e possibilidade aprofundamento análise da qualidade dos itens a validade e fidedignidade psicométrica das questões em relação a competência e à área de Linguagens, Códigos e suas Tecnologias, bem como apontamos como estudos futuros análises estatísticas desses itens do ponto de vista dos níveis de dificuldade, bem como a relação com o desempenho nos itens com o desempenho em outras áreas comparando resultados por várias características dos participantes do país.

\section{REFERÊNCIAS}

Barros, F. C., \& Silva, M. C. (2013). Conhecimento sobre atividade física e fatores associados em adolescentes estudantes do Ensino Médio da zona rural. Revista Brasileira de Atividade Física \& Saúde, 18(5), 594-603. Recuperado de http://dx.doi.org/10.12820/rbafs.v.18n5p594.

Beltrão, J. A. (2014). A Educação Física na escola do vestibular: as possíveis implicações do ENEM. Movimento, 20, 819-840. Doi: http://dx.doi.org/10.22456/1982-8918.41801

Brasil. (2012), Ministério da Educação. Instituto Nacional de Estudos e Pesquisas Educacionais Anísio Teixeira. Matriz de referência do ENEM. Recuperado de http://download.inep.gov.br/educacao_basica/enem/downloads/2012/matriz_referencia_e 
nem.pdf.

Brasil. (1998a). Ministério da Educação e do Desporto. Portaria no 438, de 1 de junho de 1998. Institui o Exame Nacional do Ensino Médio - ENEM. Brasília, DF. Recuperado de http://www.crmariocovas.sp.gov.br/pdf/diretrizes_p0178-0181_c.pdf.

BRASIL. (1998b). Secretaria de Educação Fundamental. Parâmetros curriculares nacionais: Educação Física. Brasília, DF: MEC/SEF. Recuperado de http://portal.mec.gov.br/seb/arquivos/pdf/fisica.pdf.

Brasil. (2000). Ministério da Educação e Cultura. Parâmetros Curriculares Nacionais: Ensino Médio. Brasília: Ministério da Educação. Recuperado de http://portal.mec.gov.br/seb/arquivos/pdf/blegais.pdf.

Brasil. (2002) Instituto Nacional de Estudos e Pesquisas Educacionais Anísio Teixeira - INEP. Exame Nacional do Ensino Médio - ENEM: documento básico. Brasília. Recuperado de http://portal.inep.gov.br/documents/186968/484421/ENEM++Exame+Nacional+do+Ensino+ M\%C3\%A9dio+documento+b\%C3\%A1sico+2002/193b6522-cd52-4ed2-a30f-

24c582ae941d?version=1.0.

Brasil. (2010). Instituto Nacional de Estudos e Pesquisas Educacionais Anísio Teixeira - INEP. Provas $e$ gabaritos. Recuperado de download.inep.gov.br/educacao_basica/enem/provas/2010/AZUL_quintafeira_GAB.pdf.

Brasil. (2012). Instituto Nacional de Estudos e Pesquisas Educacionais Anísio Teixeira. Provas e gabaritos. Recuperado de http://download.inep.gov.br/educacao_basica/enem/provas/2012/caderno_enem2012_do m_azul.pdf.

Brasil. (2015). Instituto Nacional de Estudos e Pesquisas Educacionais Anísio Teixeira. Provas e gabaritos. Recuperado de http://download.inep.gov.br/educacao_basica/enem/provas/2015/CAD_ENEM\%202015_DI A\%202_07_AZUL.pdf.

Brasil. (2015). Instituto Nacional de Estudos e Pesquisas Educacionais Anísio Teixeira - INEP. Ministério da Educação. Edital № 6, de 15 de maio de 2015. Exame Nacional do Ensino Médio - ENEM 2015. Recuperado de https://www.ufmg.br/sisu/wpcontent/uploads/2015/05/edital_enem_2015.pdf.

Cardoso, M. A., Pereira, F. M., Afonso, M. R., \& Rocha Junior, I. C. (2014). Educação Física no ensino médio: desenvolvimento de conceitos e da aptidão física relacionados à saúde. Rev Bras Educ Fís Esporte, 28(1), 147-61. Doi: http://dx.doi.org/10.1590/S180755092014000100147.

Cintra, E. P., Marques Júnior, A., \& Sousa, E. C. (2014). Análise dos itens de Química do ENEM com base na Taxonomia de Bloom. In 37̣ Reunião Anual da Sociedade Brasileira de Química. Recuperado de http://www.sbq.org.br/37ra/cdrom/resumos/T2451-1.pdf.

Corti, A. P. (2013). As diversas faces do ENEM: análise do perfil dos participantes (1999-2007). Estudos em Avaliação Educacional, 24(55), 198-221.

Decian, M. R., Ivo, A. A., \& Marin, E. C. (2015). O jogo como conteúdo no currículo de cursos de Educação Física - licenciatura. Pensar a Prática, 18(1). Doi: https://doi.org/10.5216/rpp.v18i1.31238.

Fernandes, A., Rodrigues, H. A., \& Nardon, T. A. (2013). A inserção dos conteúdos de Educação Física no ENEM: entre a valorização do componente curricular e as contradições da democracia. Motrivivência, (40), 13-24. Doi: http://dx.doi.org/10.5007/21758042.2013v25n40p13.

Fensterseifer, P. E., González, F. J., \& Silva, S. P. (2013). Educação Física nas avaliações em larga 
escala brasileiras: balanço e desafios. In Instituto Nacional de Estudos e Pesquisas Educacionais Anísio Teixeira. (Org.). Avaliações na Educação Básica em debate: ensino e Matrizes de Referências das avaliações em larga escala. Brasília: INEP.

Gonçalves JR, W. P., \& Barroso, M. F. (2014). As questões de física e o desempenho dos estudantes no ENEM. Revista Brasileira de Ensino de Física, 36(1), 1-16. Doi: http://dx.doi.org/10.1590/S1806-11172014000100017.

Guedes, J. E. R. P., \& Guedes, D. P. (1997). Características dos programas de Educação Física Escolar. Revista Paulista de Educação Física, 11(1), 49-62. Recuperado de http://citrus.uspnet.usp.br/eef/uploads/arquivo/v11\%20n1\%20artigo5.pdf.

Guedes, D. P. (1999). Educação para a saúde mediante programas de Educação Física escolar. Motriz, 5(1). Recuperado de http://www.rc.unesp.br/ib/efisica/motriz/05n1/5n1_ART04.pdf.

Hernandes, J. S., \& Martins, M. I. (2013). Categorização de questões de física do novo ENEM. Cad. Bras. Ens. Fís., 30(1), 58-83. Doi: 10.5007/2175-7941.2013v30n1p58.

Macedo, L. (2005). Competências e habilidades: elementos para uma reflexão pedagógica. In: Instituto Nacional de Estudos e Pesquisas Educacionais Anísio Teixeira. Exame Nacional do Ensino Médio (Enem): fundamentação teórico-metodológica. Brasília: 0 Instituto. Recuperado de http://portal.inep.gov.br/documents/186968/484421/ENEM++Exame+Nacional+do+Ensino+M\%C3\%A9dio+fundamenta\%C3\%A7\%C3\%A3o+te\%C3\%B3rico -metodol\%C3\%B3gica/449eea9e-d904-4a99-9f98-da804f3c91f5?version=1.1.

Macêdo, P. P., Souza, F. J. R., Alves Junior, T. A., Letieri, R. V., Silva Neto, L. V., Trompieri Filho, N., \& Pontes Jr, J. A. F. (2014). A musculação como conteúdo nas aulas de Educação Física Escolar. Coleção Pesquisa em Educação Física, 13(4), 15-22. Recuperado de http://www.editorafontoura.com.br/periodico/vol-13/Vol13n4-2014/Vol13n4-2014-pag-1522/Vol13n4-2014-pag-15-22.pdf.

Marcelino, L. V., \& Recena, M. C. P. (2011). Análise de questões do novo Enem segundo a Taxonomia Revisada de Bloom. In 34ํ Reunião Anual da Sociedade Brasileira de Química, 34. Florianópolis: SBQ. Recuperado de www.sbq.org.br/34ra/34RASBQ.pdf.

Mattos, M.G., \& Neira, M.G. (2008). Educação Física Infantil: Construindo o Movimento na Escola. São Paulo: Phorte.

Melo, A. V., Araújo, M. F. F., Santos, A. S., Carvalho, F. C., \& Costa, E. S. A. (2014). A temática do desenvolvimento sustentável nas provas do Enem (2009-2011): identificação das competências e habilidades nas questões das ciências da natureza e suas tecnologias. Revista da SBEnBIO, (7), 661-672. Recuperado de http://www.sbenbio.org.br/wordpress/wpcontent/uploads/2014/11/R0069-1.pdf.

Melo, R. Z., \& Ferraz, O. L. (2007). O novo ensino médio e a Educação Física. Motriz, 13(2), 86-96. Recuperado de http://www.periodicos.rc.biblioteca.unesp.br/index.php/motriz/article/view/753/756.

Minayo, M. C. (2000). O Desafio do Conhecimento: Pesquisa qualitativa em saúde. São Paulo: Hucitec.

Minhoto, M. A. P. (2008). Da disseminação da cultura de avaliação educacional: estudo sobre a institucionalização do Enem. Poiésis, 1(1), 67-85. Doi: 
http://dx.doi.org/10.19177/prppge.v1e1200867-85.

Nahas, M. V., Pires, M. C., Waltrick, A. C. A., \& Bem, M. F. L. (1995). Educação para atividade física e saúde. Revista Brasileira de Atividade Física e Saúde, 1(1), 57-65. Recuperado de: http://dx.doi.org/10.12820/rbafs.v.1n1p57-65.

Pontes Jr, J. A. F., Almeida, L. S., \& Trompieri Filho, N. (2015). Dimensão biológico-funcional da avaliação cognitiva dos conteúdos da Educação Física escolar. Revista Cientifica Internacional, 10(1). Doi: 10.6020/1679-9844/v10n1a7.

Pontes Jr, J. A. F., Sousa, L. A., \& Silva, A. G. (2015). Itens de educação física do Exame Nacional do Ensino Médio (ENEM) via taxonomia de Bloom. In VI Congresso Internacional em Avaliação Educacional: Avaliação: veredas e experiências educacionais, Fortaleza: Imprece. Recuperado de http://www.nave.ufc.br/vi_ciae/views/documentos/VI\%20CONGRESSO\%20INTERNACIONAL \%20EM\%20AVALIA\%C3\%87\%C3\%830\%20EDUCACIONAL_29\%200UTUBRO\%202015.pdf.

Pontes Jr, J. A. F. (2014). Matriz de referência para avaliação cognitiva na dimensão sociocultural da Educação Física escolar. International Journal of Developmental and Educational Psychology INFAD Revista de Psicología, 1(1), 191-200. Doi: http://dx.doi.org/10.17060/ijodaep.2014.n1.v1.362.

Santos, J. S., \& Cortelazzo, Â. L. (2013). Os conteúdos de biologia celular no Exame Nacional do Ensino Médio - ENEM. Avaliação, 18(3), 591-612. Doi: http://dx.doi.org/10.1590/S141440772013000300005.

Silva, V. A., \& Martins, M. I. (2014). Análise de questões de Física do Enem pela taxonomia de Bloom revisada. Ensaio Pesquisa em Educação em Ciências, 16(3), 189-202. Doi: http://dx.doi.org/10.1590/1983-21172014160309.

Silveira, E. F., Silva, M. C. (2011). Conhecimento sobre atividade física dos estudantes de uma cidade do sul do Brasil. Motriz, 17(3), 456-467. Doi: http://dx.doi.org/10.1590/S198065742011000300009.

Sousa, L. A., Sobral, A. E. B., \& Trompieri Filho, N. (2015). Educação Física em avaliação de larga escala: o caso do Exame Nacional do Ensino Médio - ENEM. Educação \& Linguagem, (1), 6071. Recuperado de http://www.fvj.br/revista/wpcontent/uploads/2015/10/5_Educ_2015_1.pdf.

Souza Júnior, O. M., Diniz, I. K. S., Ditomaso, A., \& Darido, S. C. (2012). Educação Física no Enem: análise das questões à luz dos PCNs. In $V$ Colóquio de Pesquisa Qualitativa e Motricidade Humana; II Congresso Internacional de Educação Física, Esporte e Lazer, 345-355. Recuperado de http://www.motricidades.org/conference/index.php/cpqmh/5cpqmh.

Souza, K. L. G. M., \& Stamatto, M. I. S. (2014). A história do tempo presente no Exame Nacional do Ensino Médio (1998-2012): um mapa de conceitos, competências e habilidades. Cadernos do Tempo Presente, (16), 12-25. Recuperado de https://seer.ufs.br/index.php/tempo/article/view/2799/2439. 
Spohr, C. F., Fortes, M. O., Rombaldi, A. J., Hallal, P. C., \& Azevedo, M. R. (2014). Atividade física e saúde na Educação Física escolar: efetividade de um ano do projeto "Educação Física +". Rev Bras Ativ Fis e Saúde, 19(3), 300-313. Doi: http://dx.doi.org/10.12820/rbafs.v.19n3p300.

Vianna, H. M. (2003). Avaliações nacionais em larga escala: análises e propostas. São Paulo: DPE.

Zancha, D., Magalhães, B. S., Martins, J., Silva, T, A., \& Abrahão, T. B. (2013). Conhecimento dos professores de educação física escolar sobre a abordagem saúde renovada e a temática saúde. Conexões: revista da Faculdade de Educação Física da Unicamp, 11(1), 204-217. Doi: http://dx.doi.org/10.20396/conex.v11i1.8637638. 